\title{
Escaping the Natural Attitude About Gender
}

\author{
Robin Dembroff \\ Yale University
}

\begin{abstract}
First question: who is speaking?... Who derives from it his own special quality, his prestige, and from whom, in return, does he receive if not the assurance, at least the presumption that what he says is true?
\end{abstract}

Foucault (1972) $)^{1}$

\begin{abstract}
Alex Byrne's article, “Are Women Adult Human Females?”, asks a question that Byrne treats as nearly rhetorical. Byrne's answer is, 'clearly, yes'. Moreover, Byrne claims, woman is a biological category that does not admit of any interpretation as (also) a social category. It is important to respond to Byrne's argument, but mostly because it is paradigmatic of a wider phenomenon. The slogan "women are adult human females" is a political slogan championed by anti-trans activists, appearing on billboards, pamphlets, and anti-trans online forums. In this paper, I respond to Byrne's argument, revealing significant problems with its background assumptions, content, and methodology.
\end{abstract}

\section{Introduction}

The title of Alex Byrne's article, "Are Women Adult Human Females?", asks a question that Byrne treats as nearly rhetorical. Byrne's answer is, 'clearly, yes'. Moreover, they claim, woman is a biological category that does not admit of any interpretation as (also) a social category. ${ }^{2}$

The content of and logical connections within Byrne's argument are often unclear and contain internal inconsistencies. In order to respond to an argument, though, such inconsistencies and vagaries must be interpreted. In that spirit, I provide and respond to what I think is a charitable reconstruction of Byrne's argument. However, I do so not solely, or even primarily for the purpose of responding to Byrne per se: this reconstructed argument, or its nearby relatives, are regularly repeated in social, political, and personal contexts. The slogan "women are adult human females" is literally that: a

\footnotetext{
${ }^{1}$ (Foucault 1972), p. 181. Cited in (Brison 2019).

2 Throughout this paper, I use 'they' as a singular, gender-neutral pronoun. See (Dembroff and Wodak 2018) for a philosophical criticism of gender-specific pronouns.
} 
political slogan. Moreover, it is a slogan that has been championed by anti-trans activists, appearing on billboards, pamphlets, and anti-trans online forums. ${ }^{3}$ It is important to respond to Byrne's argument, but mostly because Byrne's argument is a paradigmatic instance of a wider phenomenon. So while I directly address Byrne in what follows, many of my arguments apply also to others who make the same or similar arguments. ${ }^{4}$

My reconstruction of Byrne's argument is as follows:

Premise 1: There is one meaning of 'woman' relevant for philosophical inquiry into the meaning of the term 'woman'.

Premise 2: That meaning is the "standard" (or "dominant") meaning. ${ }^{6}$

Premise 3: On the "standard" meaning of 'woman', 'woman' refers to the category adult human female. ${ }^{7}$

Premise 4: Adult human female is a biological and not social category. ${ }^{8}$

Premise 5: Therefore, the single philosophically relevant meaning of the term 'woman' refers to a biological and not social category -- namely, adult human female. $[1,2,3,4]$

\footnotetext{
${ }^{3}$ See also (Corredor 2019) for discussion of far-right political groups' exploitation of anti-trans rhetoric.

${ }^{4}$ For this reason, most references to 'Byrne' can be read as shorthand for 'Byrne and those who make similar arguments'.

${ }^{5}$ Byrne (2020) frequently refers to "the meaning" of 'woman'. See also p. 19, footnote 29: "If AHF has two interpretations--corresponding to the dominant and resistant meanings of 'woman'--the one clearly at play in the relevant literature is the first." Byrne also refers to resistant meanings as "non-standard" and dominant meanings as "ordinary".

${ }^{6}$ See pp. 18-19, footnote 29. It is also worth noting that although Byrne acknowledges that people use gender terms in a variety of ways and that the meanings of these terms are "disputed", they interpret anecdotal data as showing that some people "systematically misapply" gender terms. Byrne does not consider their own uses of gender terms as potential instances of such misapplication.

${ }^{7}$ The entirety (or near entirety) of Byrne's section 2 defends Premise 3. While some of the arguments in this section are presented under the guise of epistemological arguments, I argue that these are simply disguised linguistic arguments (see my footnote 10). But even if one is not convinced, one could re-run Premises 1-6 with appeals to the "standard" concept of woman (rather than meaning of 'woman'), in order to reflect these supposedly epistemological arguments.

${ }^{8}$ Byrne, p. 3: "[The] thesis of this paper is that woman is a biological (and not social) category, and that AHF is close enough." See also p. 3, footnote 7: "Some argue that categories like female are social categories... This position is assumed false here..."
} 
Premise 6: The philosophically relevant meaning of the term 'woman' is a reliable guide to the category woman. ${ }^{9}$

Conclusion ("AHF"): The category woman is the biological and not social category adult human female. [5, 6]

I argue that this argument fails at three crucial steps: the semantic step (premises 1, 2, \& 3 ), the step from semantics to metaphysics (premise 6), and the metaphysical step (premise 4). While I don't address the key premises (1, 2, 3, 4, and 6) one-by-one, I show that the arguments supporting these premises are at best confused -- more often, they are question-begging or false. In conclusion, I take a step back to consider larger methodological and ethical lessons that can be learned from Byrne's paper.

Before proceeding, I should pause to acknowledge that Byrne claims at one point that their thesis is the "purely modal" thesis that the categories woman and adult human female are necessarily equivalent, and that they make no claims about "grounding, real definition, a prioricity, or synonymy." ${ }^{10}$ Given this, one might worry that my reconstruction distorts Byrne's argument, since the claim I've called Byrne's "conclusion" is a claim about identity, and not necessary coextension. And, as many contemporary metaphysicians hold, necessary equivalence is importantly distinct from identity. However, Byrne disagrees with these metaphysicians. Byrne takes necessary equivalence to be the same as identity, explicitly claiming that "necessarily equivalent categories are identical". ${ }^{11}$

This alone would provide sufficient justification for describing Byrne's thesis as one about identity. In addition, though, note that, if Byrne's thesis were about coextension and not identity, their argument would be hopelessly invalid. Throughout their paper, Byrne argues that adult human female is a "biological not social" category, and then concludes that woman is a "biological not social" category (p. 7). If Byrne's thesis were merely that adult human female and woman are coextensive, this line of reasoning would be incorrect. Just consider Kit Fine's (1994) example of two necessarily equivalent but distinct entities: the unit set of Socrates and Socrates. It would be incorrect to claim that, because the unit set of Socrates has a single member, Socrates must also have a single member. Modal equivalence of two entities does not guarantee

\footnotetext{
${ }_{9}^{9}$ Byrne, p. 2: "[T]here is nothing wrong with appealing to linguistic evidence that clearly bears on the meaning (or intension) of 'woman', since that has immediate implications for AHF via disquotational principles." Notice that Byrne refers to "the" meaning of "woman, per Premise 1. Bafflingly, Byrne denies that "ordinary use" of 'woman' is "evidence" for or against AHF, but then proceeds to provide arguments for AHF that entirely rely on particular, everyday uses of 'woman' and 'girl'.

${ }^{10}$ Byrne p. 2.

${ }^{11}$ Byrne p. 2, fn 2: ("It will do no harm to individuate categories modally: necessarily equivalent categories are identical.")
} 
that they have all the same features - this guarantee requires identity. Given, then, that Byrne infers that woman is a "biological and not social" category from the claim that adult human female is a "biological and not social" category, Byrne's thesis must be one about identity.

\section{The Semantic Step}

Byrne's argument rests on a semantic claim: the philosophically relevant meaning of 'woman' refers to adult human female. ${ }^{12}$ In section 2, and in the span of less than five pages, Byrne provides six arguments supporting this semantic claim. ${ }^{13}$ These arguments are as follows:

1. AHF reproduces the dictionary definition of 'woman'.

2. One would expect English to have a word that picks out the category adult human female, and 'woman' is the only candidate.

3. AHF explains how we sometimes know that an individual is a woman, despite knowing nothing else relevant about her other than the fact that she is an adult human female.

4. AHF stands or falls with the analogous thesis for girls, which can be supported independently.

5. AHF predicts the correct verdict in cases of gender role reversal

6. AHF is supported by the fact that 'woman' and 'female' are often appropriately used as stylistic variants of each other, even in hyperintensional contexts. ${ }^{14}$

\footnotetext{
${ }^{12}$ Byrne's arguments for this claim simply disregard or ignore the testimony and scholarship of all those whose language use conflicts with Byrne's claim, not least of which includes trans and queer persons, persons with intersex variations, and scholars who specialize in gender and sexuality. (More on this in Section 5.)

${ }^{13}$ Byrne might protest that three of these six arguments (2.3, 2.4, and 2.5) are not semantic arguments, but rather, arguments that appeal to "facts about where the women are". These three arguments are meant to show that someone knows that someone is a woman if they know that person is an adult human female, thereby supporting AHF's sufficiency direction. First, note that one typically can know that someone is a woman by knowing that that the person is a lesbian, a wife, a mother, or a sister. Supporting the sufficiency direction of AHF is highly uninformative. Second, these arguments reduce to appeals to semantic intuitions, insofar as they are arguments at all. For example, two of these arguments (2.3 and 2.5) appeal to what are stipulated as "correct" descriptions of persons as falling under the term 'women', as well as intuition pumps about what counterfactual statements "ordinary" people (people who share Byrne's linguistic intuitions?) would assent to. Arguably, the third argument (2.4) rests on linguistic intuitions as well, as it simply stipulates that a female-assigned baby is "known" to be a girl. If this argument has more content than the claim that people use the term 'girl' to describe female-assigned babies, I couldn't find it.

${ }^{14}$ Claims 1-6 are, respectively, the headings of Byrne's Sections 2.1-2.6.
} 
Rather than go through arguments 1-6 one-by-one, I will focus on three problems that are threaded throughout these arguments.

\section{Problem 1: Framing}

Byrne's paper frequently refers to "the meaning" of the term 'woman'. This is no accident: the paper takes for granted that gender terms like 'man' and 'woman' each have a single, invariant meaning. In fact, the main body of the paper does not mention the possibility that gender terms have multiple or contextual meanings. This is particularly striking given that, as Byrne observes, uses of gender terms vary widely and are contentious. This observation appears to be evidence in favor of a polysemous or contextualist approach to gender terms -- that is, an approach on which gender terms either have multiple, related meanings, or have meanings relative to contexts that have variant standards. Unsurprisingly, these are the two approaches so far defended in the existing philosophical literature on the semantics of gender terms. ${ }^{15}$

Despite this evidence, and despite the existing literature defending polysemous or contextualist accounts of gender terms, Byrne's argument proceeds with the unargued-for assumption that there is one, unvarying answer to the question What does the word 'woman' mean? Byrne even suggests we will find this meaning in the pages of a dictionary. ${ }^{16}$ In short, Byrne simply assumes that the views best supported by linguistic evidence, which are (non-accidentally) views defended in the existent literature are irrelevant to philosophical inquiry into the semantics of gender terms.

One might be able to forgive this philosophically naive framing from a newcomer to philosophical thinking about gender, were it not for the fact that Byrne acknowledges in footnotes that they are aware of polysemic and contextualist views of gender terms. For example, at one point, Byrne raises Saul's (2012) contextualist position. However, they do not respond at all to the contextualist position, and only take issue with the idea that contextual standards for correct use of 'women' could include transgender women. ${ }^{17}$ In a different footnote, Byrne recognizes Bettcher's (2013) position

${ }^{15}$ See (Bettcher 2013; Saul 2012; Diaz-Leon 2016; Barnes 2019; Laskowski 2020; Dembroff forthcoming)

${ }^{16}$ See section 2.1.

${ }^{17}$ Of course, as (Bettcher 2013) and Dembroff (forthcoming) both point out, gender terms like 'woman' do systematically extend to trans women within trans-inclusive communities. Byrne ignores this contradicting evidence and instead offers two cursory arguments: (1) There could not be a contextual meaning of 'girls' that secure simultaneous reference to both trans girls and female-assigned babies; and (2) an identity-based meaning of 'woman' would result in circularity when it came to specifying who is a woman, since the answer would be 'those who identify as a woman'. The first argument displays a startlingly uncharitable reading of Saul, who suggests that meaning might be fixed by standards "relevant similarity" to those possessing female-coded bodies, never once claiming that these standards could not be ambiguous, disjunctive, vague, or 
that gender terms take on distinct meanings in trans-inclusive communities. Their response is to dismiss this as irrelevant to philosophical inquiry. Even if there are multiple meanings of gender terms, Byrne asserts, the meaning "clearly in play in the relevant literature" is the "dominant" meaning. ${ }^{18}$ By "dominant" meaning, it is safe to presume that Byrne means a meaning that best accords with their own linguistic intuitions -- as well as dominant power structures. But, in that case, Byrne's claim that these are the meanings at play in the "relevant literature" is puzzling. I cannot help but wonder why work by the central figures of the philosophical literature, not to mention work by anthropologists, sociologists, and linguists, is "irrelevant", and where this elusive "relevant literature" is to be found. ${ }^{19}$ In any case, I see no motivation--other than question begging--for admitting that 'woman' may have multiple meanings, but insisting that one's own thesis picks out the philosophically 'relevant' one. ${ }^{20}$

\section{Problem 2: Cherry-picked data and question begging}

Gender terms like 'woman' are sometimes used to refer to persons' physiological features. Such uses are evidence that, in certain contexts and communities, these terms take on meanings that entail or include physiological features. But this in no way shows that gender terms have one -- or one philosophically relevant -- meaning. "Dominant" uses of gender terms -- by which I take Byrne to mean use outside of trans communities and gender studies -- vary widely. As Elizabeth Barnes observes:

Common usage of gender terms is currently in flux...[so] it's difficult to settle on what, if anything, 'the folk' or 'ordinary speakers' mean by their gender terms. Teenagers probably mean something quite a bit different from their grandparents; wealthy teenagers in Manhattan probably mean something quite a bit different from working class teenagers in Alabama. ${ }^{21}$

Even mainstream sources such as national newspapers -- including the New York Times, which Byrne appeals to multiple times -- frequently use gender terms in ways that misalign with the claim that 'woman' (always) refers to adult

underdetermined within a given context. The second argument, in turn, simply ignores the existing literature on gender identity, which provides substantive and non-circular accounts of what it means to "identify as a woman". (Jenkins 2018) and (Bettcher 2009), for example, directly address the circularity worry.

${ }^{18}$ Byrne, p. 19, fn. 29

${ }^{19}$ E.g., See the fields of sociolinguistics of gender and LGBT linguistics, and especially the work of Lal Zimman, such as (Zimman 2014).

${ }^{20}$ For a richer critique of philosophy's tendency toward myopism, see (Dotson 2012)

${ }^{21}$ (Barnes 2019), 9. 
human female. ${ }^{22}$ So how can Byrne (or anyone) maintain that 'woman' has one dominant meaning?

The answer is 'cherry-picked evidence'. By 'cherry-picked', I mean both appeals to anecdotal instances of natural language use that align with this claim, and dismissal of natural language use that do not align with this claim. For example, Byrne claims that "the dictionary" definition provides evidence that 'woman' means 'adult human female'. ${ }^{23}$ Let's set aside problems with using the dictionary to do philosophy of language. Even dictionaries list multiple meanings for 'woman'. ${ }^{24}$ Byrne also appeals to The New York Times, a 2010 Pourriat film, a 2003 Vincent memoir, and a carefully chosen quotation from a trans author, Julia Serano. ${ }^{25}$ They dismiss (as 'irrelevant', perhaps?) the language use of feminist philosophers, as well as entire linguistic communities where 'woman' is explicitly not used to mean 'adult human female' (at least, not as Byrne interprets 'adult human female'). More strikingly, though, Byrne's argument ignores the endless examples of instances within "dominant" contexts, such as in law, print media, social media, policy documents, and education, where 'woman' is used with meanings other than adult human female. ${ }^{26}$

\footnotetext{
${ }^{22}$ See, e.g. (Thomas 2019): “Author David Thomas still lives as a man, but has begun the male-to-female gender transition that will eventually result in becoming a woman." See also (Fadulu and Flanagan 2019): "At least 22 transgender people have been fatally shot or killed in 2019 ... Nearly all of them were black women."

${ }^{23}$ Byrne, p. 4, "AHF reproduces the dictionary definition of 'woman'". It's unclear which dictionary Byrne is referencing. None of the dictionaries I looked at, including the Oxford English Dictionary and Mirriam-Webster's Dictionary, defined 'woman' as "adult human female", making it particularly obvious that Byrne is defending a political slogan.

${ }^{24}$ Miriam-Webster's, for example, lists six, including the quite obviously social meaning, "distinctively feminine nature". This aligns with (Bettcher 2009)'s point that terms like 'womanly' show that cultural meanings are "packed right into" the meaning of 'woman' -- a point that Byrne first misrepresents as entailing that "'Ditch digging is womanly' is necessarily false", and then dismisses purely on the grounds that it "is debatable" -- an assertion that certainly leaves something to be desired qua philosophical argument. (P. 11, footnote 15) Moreover, Bettcher is by no means alone in their observation. As an anonymous referee pointed out, Beauvoir, in the introduction to The Second Sex, also argues that the term 'woman' (or, more precisely, 'femme') encodes evaluative content.

${ }^{25}$ Section 2. Later in the paper (pp. 16-17), Byrne also appeals to cherry-picked examples of trans writers' uses of 'woman' and 'man' as evidence for his claim that trans people are not of one mind on how to understand the relationship between trans identities and dominant gender categories. ("...trans women themselves are not of one mind on [the claim that trans women are women].") However, Byrne ignores the fact that, in the very same quotations, one finds uses of 'woman' that conflict with the thesis that 'woman' means 'adult human female'.

${ }^{26}$ Byrne might respond that this just shows that who counts as an 'adult human female' differs across contexts. This response would undermine their insistence that adult human female is a "biological and not social" category, since presumably a "biological and not social" category would not consistently differ in nature and extension across contexts. See Section 4.
} 
To cover up this cherry-picked use of evidence, Byrne often describes their selected examples as "correct", as "knowledge", or as "appropriate". While those who endorse polysemic or contextualist approaches need not contest these descriptions, such descriptions, combined with Byrne's stipulation that 'woman' has a single, invariant meaning, amount to question begging at best, and rhetorical bullying at worst. ${ }^{27}$ And while it is clever to attempt to escape charges of question begging simply by predicting them, this sleight of hand does not actually make one immune to such charges. ${ }^{28}$

Finally, and in a different vein of "cherry-picking", it is revealing to notice that Byrne never extends their semantic inquiry to the vast majority of gender terms, instead focusing exclusively on 'woman', 'girl', and occasionally, 'man'. Why not include, for example, 'lady', 'miss', 'mister', 'widow', 'tomboy', 'lesbian', 'lad', etc.? I suspect Byrne's response will be that these terms refer to the conjunction of woman, girl, boy, or man -categories Byrne argues are "biological and not social" -- with social information, such as class, marital status, gender presentation, or sexuality. But let's examine this more closely. For example, what is this 'non-social' distinction between those called 'girls' and those called 'women'? Byrne proposes an answer: those called 'girls' are "juvenile", rather than "adult" human females, where the difference between "juvenile" and "adult" is a "biological and not social" difference. But what could this purely biological difference be? The most plausible answer, it seems, is sexual maturity. But, in that case, the most charitable version of Byrne's view is that what distinguishes those correctly called 'girls' from those correctly called 'women' is whether or not the given individuals have reached a point of physical maturity associated with being impregnatable. (I see no point in mincing words.)

Even setting this aside, the claim that there is a biological difference - or a difference at all — between those called 'girls' and those called 'women' conflicts with even "dominant" uses of these terms. 'Woman' is rarely used to describe pubescent adolescents, such as fifteen- and sixteen-year-olds. And 'girl' is used not only for children, but also for adolescents and adults. ${ }^{29}$ As the linguist Robin Lakoff wrote in

\footnotetext{
${ }^{27}$ For example, Byrne stipulates that physiology-based uses of 'woman' and 'man' in gender role reversal cases is "correct" (Section 2.5, "AHF predicts the correct verdict in cases of gender role reversal"), and later appeals to this stipulation to dismiss out of hand Talia Bettcher's argument that in role reversal cases "it isn't clear how to apply the terms 'man' and 'woman'." (Byrne p. 12, cf Bettcher 2009: 103-4).

${ }^{28}$ Byrne, p. 3: "People vary in their abilities to correctly identify members of categories, or to correctly apply words. Woman and 'woman' are no exceptions... It can be tempting to respond to such disagreement by losing one's nerve and retreating to the claim that one's evidence really consists in neutrally characterized facts about speakers' use of words, or (perhaps worse) facts about "intuitions" - evidence that one's opponents are less likely to challenge. That temptation should be resisted. Pointless charges of "begging the question" may be anticipated; this paper does not attempt the futile task of convincing everyone." Emphasis added.

${ }^{29}$ See (Lakoff 1973), 61: “[W]omen of all ages are 'girls'.” While Lakoff claims that this does not hold true for 'boy' and 'man', this overlooks the important fact that, historically in the U.S., 'boy'
} 
1973, 'girl' is a "common substitute" for 'woman'. ${ }^{30}$ 'Girl' also is frequently used as a term of endearment within groups of both female-identified friends (as well as male-identified gay friends). And the term 'girlfriend', needless to say, is not typically used for children. Byrne's claims about the meanings of these terms fail to track even dominant use.

\section{The Bridge From Semantics to Metaphysics}

Byrne's conclusion is a metaphysical one: a woman is an adult human female, where adult human female is a "biological and not social" category. I'll address the substance of this claim in the next section. The purpose of this section is to address a mostly hidden premise in Byrne's argument, which I state explicitly as Premise 6. This premise says that the "philosophically relevant" meaning of the term 'woman' is a reliable guide to the metaphysics of the category woman. (Byrne assumes there is only one such category.) In addressing this premise, I grant, for the sake of argument, that there is a single meaning of the term 'woman' that is philosophically relevant. We could even grant that this is the "dominant" meaning, and the problem remains: one cannot read the metaphysics of gender off "the meaning" of natural language gender terms.

Barnes (2019) describes the project of the metaphysics of gender as the project of saying "what feature(s) of the world - if any - unify or explain gender." ${ }^{131}$ But there are at least two reasons for thinking that everyday use of gender terms is a poor guide to such features. The first is discussed at length by Barnes, who writes:

A striking feature of the contemporary metaphysics of gender...is that it typically takes the task of explaining gender as the task of explaining what it is to be a woman (or a man, or genderqueer, or etc.) And thus attempts to give a metaphysics of gender often become attempts to give application conditions for gender terms such as 'woman' ... But [giving a metaphysics of gender] might come apart from the project of defining or giving application conditions for our natural language gender terms like 'woman'. ${ }^{32}$

has been a common substitute for 'man' when referring to black men. These substitutions share derogation in common.

${ }^{30}$ (Lakoff 1973), 61. This is particularly notable, given that one of Byrne's six arguments in favor of AHF (2.6) is that 'woman' and 'female' are used interchangeably.

${ }^{31}$ (Barnes 2019), p. 2. Barnes takes this to mean the attempt to "theorize what it is in virtue of which people have genders, or in virtue of which members of a given gender can be said to have something in common with each other, or in virtue of which gendered norms and roles have the significance they do."

32 (Barnes 2019), pp. 2, 3. Barnes's critique does not apply to Haslanger's (2000) analysis, which seeks a real definition of gender categories, and not a semantic analysis of gender terms. While 
Barnes devotes an entire section of their paper to arguing that the semantics of natural language gender terms pull apart from the metaphysics of gender. ${ }^{33}$ Barnes points to the already "commonplace" position within other areas of metaphysics that natural language use is a poor guide to metaphysical facts: true sentences of natural language and the extensions of natural language predicates do not reveal, and need not even map onto, metaphysical structure. ${ }^{34}$ To illustrate this, Barnes points to the popular debate in mereology over the existence and nature of ordinary objects, such as tables. While some metaphysicians are committed to providing paraphrases of the natural language term 'table' that align with their metaphysics, increasingly many deny the need for such paraphrasing. ${ }^{35}$ Words get their meanings and application conditions from their everyday use, and we have little to no reason to believe that such everyday use would glom onto the metaphysical structures that ultimately explain the phenomena that people refer to using natural language. Similarly, Barnes goes on to argue, doing the metaphysics of gender means understanding the "bedrock social structure" that gives rise to the "complicated, multi-faceted social experience of gender." As with 'table', we have little to no reason to believe that the extension of natural language terms like 'woman' map neatly onto this structure. ${ }^{36}$

In addition to Barnes's argument, there is another, largely undiscussed reason to think that natural language terms are a poor guide to the metaphysics of gender: ${ }^{37}$ in many contexts, gender terms function less as descriptive terms, and more as what political and critical theorists call "floating signifiers". ${ }^{8}$ Such signifiers are, in brief, signifiers that carry robust social or political connotations without a specific signified or

Haslanger describes these categories with the terms 'women' and 'men', this is because they hold that we can and should appropriate the terms 'women' and 'men' for these metaphysical categories.

${ }^{33}$ Byrne fails to even acknowledge, much less address, this argument.

${ }^{34}$ (Barnes 2019), p. 9.

${ }^{35}$ Barnes cites paraphrasers Van Inwagen (1990) and Merrick (2001). They point to Bennett (2011), Cameron (2008), Dorr (2005), Schaffer (2009), and Sider (2011) as examples of metaphysicians denying the need for natural language paraphrasing.

${ }^{36}$ (Barnes 2019), p. 14. Also, as an anonymous referee pointed out to me, Byrne's assumption that ordinary language use is a direct guide to metaphysics is most dubious with respect to non-social kinds, and is far more plausible with respect to social kinds. There is, then, tension between Byrne's claim that woman is a non-social kind, and Byrne's assumption that we have epistemic access to the metaphysics of womanhood via ordinary language use.

${ }^{37}$ The closest discussion in the analytic literature is Dembroff (forthcoming). But see (Wittig 1985) for a similar suggestion in earlier feminist thought.

38 "Floating signifiers" are closely related to "empty signifiers", which are signifiers that attempt to become devoid of particular content in order to represent a universal, hegemonic reality. Laclau (2005) suggests that signifiers of populism, like the 'moral majority', are examples of empty signifiers. In practice, however, and as Laclau points out, empty and floating signifiers constantly overlap. (p. 43) 
referent. For example, Ernesto Laclau suggests that the term 'the people' is a floating signifier: It does not function or carry signification on the basis of differences in purely descriptive content, but rather, on the basis of having sociopolitical significance that far outstrips any such content. Or, to use Laclau's words, "what [the floating signifier] wins in extension it loses in intension." ${ }^{\prime 39}$ Laclau here points at the fact that floating signifiers are capable of taking on whatever particular descriptive content users wish to impose on them, given these users' social or political ends, all the while maintaining a stable, underlying significance. Other likely candidates for floating signifiers include racial terms like 'white' and 'black', names of political leaders like 'Obama' and 'Trump', or terms like 'democracy' and 'justice'. Such terms are not used to refer to a single object, nor do they have agreed upon descriptive content. Rather, their primary significance is sociopolitical, and they are used in relation to various objects or descriptive contents as part of broader social struggles to harness the power of their sociopolitical significance.

One helpful way of thinking about floating signifiers is as tools in what David Plunkett and Alexis Burgess call disputes over "conceptual ethics". Such disputes, on their picture, are disputes over representational (i.e., conceptual or semantic) choices, but for ethical (rather than "merely semantic") reasons. ${ }^{40}$ For example, they argue, debates over what is aptly described as the 'same person' or as 'death' are best understood as disagreements about non-representational consequences of representation, not about the form of representation per se. ${ }^{41}$ They are arguments about what we ought to do, not about the way the world is.

While I do not have space to fully argue for this claim here, we can quickly see evidence that terms like 'woman' and 'man' frequently -- if not almost always -- function as floating signifiers in debates over how people ought (or ought not) be treated on the basis of their physical, social, and psychological features. As Kessler and McKenna (1978) point out, attributions of gender -- often, via the terms 'woman' or 'man' -- set up an interpretive lens through which we evaluate a person's body, social roles, and gender identity. Two people can agree on all the facts about a given person's body, social roles, and identity, but have drastically different normative evaluations of these facts, which they communicate by describing this person as a 'woman' or a 'man'. Conservative groups insist that "there are only two genders", and that "a woman is an adult human female"; liberal groups claim that "trans women are women" and that "gender is not binary". Kessler and McKenna's point is that these groups could agree on all the underlying physical, psychological, and social facts, and still continue to make these opposing claims. This suggests that their respectives uses of terms like 'gender' and 'woman' are doing normative, political work more so than descriptive work. As Haslanger observes, "the act of classifying someone as a member of a social group

${ }^{39}$ (Laclau 2005), p. 40

${ }^{40}$ (Burgess and Plunkett 2013), p. 1092

${ }^{41}$ (Burgess and Plunkett 2013), p. 1097 
invokes a set of 'appropriate'...norms and expectations... in short, it carries prescriptive force." ${ }^{\prime 2}$ For this reason, Haslanger argues, gender terms often primarily function as a way to communicate what norms and expectations are appropriate to apply to a person or group, and not to communicate descriptive features of that person or group. ${ }^{43}$

The concept of floating signifiers is helpful for understanding the mechanism underlying this normative use of gender terms. And, assuming that gender terms do function as floating signifiers, this is enough to see why they are unreliable guides to the metaphysics of gender. Consider an analogy: suppose two people are arguing. One insists, 'Octopuses are persons' and the other denies this. They might agree on all the relevant facts about octopuses, and continue to have this dispute, because the term 'person' is functioning as a floating signifier, carrying robust moral significance that to some extent floats free of its specific referential content. In this scenario, it would be a mistake to go about the metaphysics of personhood by looking to these uses of 'person'. Floating signifiers are not intended to describe the world, but to prescribe actions, attitudes, and behaviors. Given this, if 'woman' and 'man' operate as floating signifiers -- and the evidence suggests that they do -- they are poor guides to the metaphysics of gender.

This point is particularly important in light of Byrne's own claim that, in some cases, we should describe people as "women" and treat people as women even if they are not "actually" women. ${ }^{44}$ First, this claim conflicts with Byrne's own methodology of using natural language use of 'woman' as a guide to metaphysical facts about womanhood. Second, and perhaps more importantly, this claim takes for granted that 'woman' has a stable extension, and that this extension tracks purely descriptive features. Byrne's claim thereby fails if terms like 'woman' are indeed floating signifiers, since floating signifiers lack stable extensions and are not primarily descriptive. ${ }^{45}$

Byrne does not consider the possibility that one can theorize about the metaphysics of gender using methodologies other than the analysis of natural language use. Byrne would be helped by the decades of gender theory that have grappled with this question and developed improved methodologies. One such methodology is, in fact, discussed (though misrepresented) by Byrne in their own paper -- Haslanger's ameliorative project. ${ }^{46}$ Byrne presents Haslanger's ameliorative project as a prescriptive political project that is largely disinterested in describing the world. But in fact, drawing

${ }^{42}$ (Haslanger 2000), p. 47.

${ }^{43}$ See (Haslanger 2000), p. 48: "[I]t is possible to view our gender...vocabulary as, in effect, providing terminological place-holders marking space for the collective negotiation of our social identities." On one reading of (Bettcher 2009, 110-111), Bettcher takes a similar view of gender terms according to which claims such as "I am a woman" can be speech acts that are not truth apt, and primarily communicate one's "reasons for acting" rather than a "conception of self". ${ }^{44}$ See Byrne pp. 11-12.

${ }^{45}$ Thanks to an anonymous referee for bringing this point to my attention.

${ }^{46}$ (Haslanger 2000). 
from W.V.O. Quine, Hilary Putnam, and others, Haslanger is careful to situate the ameliorative project within general metaontological and semantic commitments that entail the methodological inseparability of prescription and description. In doing so, Haslanger goes to great lengths to show that the methodology underlying the ameliorative project, despite its prescriptive element, is not different in kind than methodologies standardly deployed in other areas of metaphysics.

\section{The Metaphysical Step}

Byrne's paper concludes with metaphysical claims: a woman is an adult human female, and adult human female is a "biological and not social" category. While a small library of books problematizes these claims, I will focus on just two problems: the universal framing and the distinction between "biological" and "social" categories.

\section{Problem 1: Framing}

The framing problem with Byrne's metaphysical claim is the metaphysical analog of the framing problem with their semantic claim. For this reason, I will not spend too much time on it, but it is nevertheless important to point out.

Throughout the paper, Byrne assumes without argument that there is a single, universal category woman. This much is obvious: in addition to frequently referring to "the category woman", Byrne refers to "the prototype of woman" and "the essence of womanhood". ${ }^{47}$ This universalist assumption has been criticized by black feminist theorists, including Kimberle Crenshaw and Patricia Hill Collins. ${ }^{48}$ It also is discussed at length in Elizabeth Spelman's book Inessential Woman, Mari Mikkola's The Wrong of Injustice, and Naomi Scheman's "Queering the Center by Centering the Queer". ${ }^{49}$ There is a wealth of empirical literature in anthropology, history, sociology, and gender studies concerning alternative gender classification schemas found in non-Western societies and LGBTQ communities, as well as historical variations in understandings of women and men. ${ }^{50}$ In light of this evidence, both Bettcher (2013) and Dembroff (forthcoming) have defended metaphysical pluralism about gender categories.

Byrne disregards all of this, instead assuming that woman is a single, universal category that aligns with "dominant", Western, contemporary understanding. In order to stave off objections, Byrne ignores the historicity of Western gender categories, and uses cherry-picked quotations to undermine the legitimacy of queer communities and

\footnotetext{
${ }^{47}$ Byrne, pp. 14, 21.

48 (Crenshaw 1989; Hill Collins 2016; 2000)

${ }^{49}$ (Spelman c1988; Mikkola 2016; Scheman 1997)

${ }^{50}$ (Meyerowitz 2004) See also (Valentine 2007; Gill-Peterson 2018).
} 
non-Western cultures with nonbinary genders. ${ }^{51}$ And while I am not here claiming that gender pluralism is correct, I am pointing out that there are very good, already discussed reasons to reject a universalist framework. Responsible scholarship requires addressing these reasons, rather than stipulating their irrelevance.

\section{Problem 2: The Biological/Social Distinction}

Byrne's conclusion is not simply that 'the' category woman is the category adult human female, but also that adult human female is a "biological and not social" category. But what is this distinction? Closer examination reveals that Byrne's own understanding of what makes a category "biological" or "social" does not establish that the two are exclusive. Moreover, while Byrne gives little content to adult human female, what content there is -especially when combined with Byrne's insistence that this category is "not social" -shows that Byrne misunderstands or is unfamiliar with relevant work in social ontology, the history of sexology, gender theory, and biological and medical anthropology.

Let's begin with the supposed distinction between "biological" and "social" categories. Byrne stipulates the following definitions:

Biological categories: "[C]ategories proprietary to biology." ${ }^{\prime 52}$

Social categories: Categories with membership conditions that are at least partially constituted by social features. ${ }^{53}$

While Byrne does not define "proprietary", we can assume that it does not mean "exclusive to", given that Byrne's argument is explicitly about the everyday, "dominant" category woman, and not a technically-defined category only used in the context of biological research. So perhaps Byrne means that woman is akin to planet -- just as astronomers are (let's suppose) the relevant experts for describing what makes a

\footnotetext{
${ }^{51}$ See p. 10, fn 16, where Byrne appeals to linguistic translation (from a language with nonbinary gender terms to one with only binary gender terms) to undermine the legitimacy of nonbinary categories. ("... literal translations of berdache names do not inspire confidence: admittedly they include 'man transformed into a woman' and 'man-woman', but also 'acts like a woman', 'woman pretenders', and 'unmanly man'.") See also p. 16, where Byrne dismisses trans persons' testimonies as unreliably due to 'personal investment'. ("[W]hen someone declares 'I am an F' that is often a strong indication that she is an F. In the present [transgender] case, however, this is unpersuasive for a perfectly general reason: if someone is personally heavily invested in the truth of $p$, it is prudent to treat her claim that $p$ is true with some initial caution.") We are presumably meant to suppose that Byrne is an uninterested, objective observer.

${ }^{52}$ Byrne, p. 1, fn 2

${ }^{53}$ Or, to put this in technical terms that Byrne borrows from (Haslanger 2012) (131; cf. 87): "in order for $\mathrm{X}$ to be $\mathrm{F}, \mathrm{X}$ must exist within a social matrix that constitutes $\mathrm{F}^{\prime} \mathrm{s}^{\prime \prime}$.
} 
cosmological body a planet, biologists are the relevant experts for describing what makes a human body an adult human female.

We also are not told what makes a feature constitutively social. Presumably, though, it must be something more than simply involving a relationship between humans - after all, otherwise, every category within biology that concerns reproduction would be social. So perhaps being constitutively social, for Byrne, is not simply about relations between humans, but societal relations between humans. Even on this understanding, Byrne's biological/social distinction fails. For example, the category caste is a category used within biology to pick out subsets of animals within a society of social animals that have particular social functions and distinct anatomical or morphological features. Categories of animals defined in terms of their caste, such as workers, soldiers, or queens, are therefore defined in terms of constitutively social features.

Perhaps by "biological category", then, Byrne intended something more like "a category whose membership conditions are fully defined in terms of physiological features". Certainly, they seem to have something like this in mind, as evidenced by their placing adult human female alongside vertebrate and mammal, as well as their insistence that persons who lack uteruses and ovaries, even if they otherwise appear as "normal" females, are not adult human females. ${ }^{54}$

But if this is what Byrne means by "biological", then new problems arise. First, it is completely unclear how Byrne takes adult to have purely physiological membership conditions. Even with respect to ordinary language, such as the proliferation of terms like 'adulting', it seems clear that "adult" is very much a social category. ${ }^{55}$ Despite this, perhaps Byrne would say that adult humans are those with mature reproductive organs. In that case, though, their stipulated definition of adult human female tracks a group with a very different extension than the persons typically considered women. Insofar as Byrne's thesis is meant to be about what the dictionary and ordinary language speakers are talking about when they talk about 'women', their thesis remains false.

Second, and more importantly, the claim that adult human female is "biological and not social", in these narrow senses of "biological" and "social", fails to undermine the traditional sex/gender distinction that Byrne sets out to disprove, and also fails to address the sense of "social" (discussed below) in which Kessler \& McKenna, Butler, Karkazis, Meyerowitz, and others have argued that sex categories like female and male are importantly social categories. ${ }^{56}$ So while Byrne tries to undermine both a sex/gender

\footnotetext{
${ }^{54}$ The language of normalcy is normatively loaded, and has a long history of weaponization against ethnic and racial groups, as well as persons with disabilities. Moreover, as biomedical history and physical variations show, there is nothing that answers to description as a "normal" female body.

${ }^{55}$ Thanks to an anonymous referee for this example.

${ }^{56}$ (Butler 1993; Kessler and McKenna 1978; K. A. Karkazis 2008; Meyerowitz 2004)
} 
distinction on which sex is non-social and gender is social, as well as the view that sex (even if distinct from gender) is social, they succeed in neither.

Consider the traditional sex/gender distinction that Byrne targets. According to this distinction, someone's sex concerns what reproductive features (e.g., genitalia, gametes, gonads) they have, but their gender concerns how they are viewed and treated by others and themselves on the basis of their (perceived) sex. Byrne says nothing in the entirety of their paper to undermine this distinction: showing that there is some category such that membership is solely based on reproductive features is compatible with their being a category such that membership is based on being treated a certain way, given (perceived) reproductive features. In fact, Byrne themself acknowledges this, albeit in a confused way. They write, "[A] category can be both socially significant and biological... Female and male are clear examples." ${ }^{177}$ The whole point of the traditional sex/gender distinction was to make an analytic distinction between categories of bodies (and only bodies!) and categories of people treated according to the social significance attached to those bodies. Byrne conflates the two by referring to them as "a category". But recognizing that biological features carry social significance just is recognizing the basis of the traditional sex/gender distinction. This point bears emphasis: because the traditional sex/gender distinction just is the distinction between categories based solely on reproductive features, and categories based on the social significance of reproductive features, Byrne's admission that biological features can be "socially significant" not only fails to undermine this distinction; it aligns Byrne with those who make this distinction.

Byrne also rejects the view that sex itself is social. Despite the fact that this view has been defended at length by anthropologists and historians as well as gender scholars, Byrne again simply assumes without argument that this view is false. ${ }^{58}$ And, on the very narrow view of a "social" category that Byrne uses, it is true that sex categories are not social. But this claim is orthogonal to the relevant claim made by these scholars. Their claim was never and is not the claim that the membership conditions of sex categories include constitutively societal features, such as particular socialization or treatment. It is, rather, that there is no unique, stable, and binary classification of sex traits, that binary classification of bodies as female and male is socially motivated and typically vague, underdetermined, or ambiguous, and that these classifications are historically and contextually variable. ${ }^{59}$

Byrne's biological/social division does not, then, touch on this sense of sex as social. Nevertheless, Byrne does assume that sex is not social even in this broader sense.

\footnotetext{
${ }^{57}$ Byrne, p. 6.

${ }^{58}$ Byrne, p. 4, fn 7. ("Some argue that categories like female are social categories... This position is assumed false here...") Byrne also claims that "if female is a social category", their thesis is easier to defend. Given that their thesis is, in their own words, the thesis that "woman is a biological (and not social) category"--namely, adult human female--I'm unsure how to interpret this claim. ${ }^{59}$ As an anonymous referee noted, these difficulties are not unique to sex classification - they also are mirrored in species classification. See, e.g., Kitcher (1984) and Ereshefsky (1998).
} 
They take adult human female and adult human male to be universal, stable, and discrete categories of sex traits, where a single set of sex traits are shared among all women, and where these categories can be explained without reference to cultural ideologies. Each of these claims is false.

First, there are no such stable, discrete, and exhaustive categories of sex traits. Historian Joanne Meyerowitz makes this point clearly:

[L]ike gender and sexuality, biological sex has a history. Humans have imagined it differently at different times and in different places. European and American scientists once envisioned sex as a hierarchy of similar beings in which female stood as an inferior version of male. With the Enlightenment of the late eighteenth century, though, they increasingly wrote of two sexes, distinct and opposite. Female less often appeared as a paler copy of male and more often as distinctly different and complementary. ${ }^{60}$

As Meyerowitz (along with others) shows in detail, categorizations of sex traits under the labels 'female' and 'male' have and continue to fluctuate across time and social context. For example, with the discovery of sex hormones and sex chromosomes, sexologists turned from "the visible realm of genitals to the microscopic gaze" to embark on a still ongoing "elusive quest" to find stable grounds for binary, exhaustive sex categorization. ${ }^{61}$ And, while sexologists go about this miscroscopic search, doctors and nurses continue to assign sex categories on the basis of genitals, in some cases following genital reconstructive surgery on infants with intersex variations. ${ }^{62}$ In short, across and even within scientific and medical fields, there is no agreement or stability with respect to the grounds for sex categorization..$^{63}$ The details of recent legal battles over whether sprinters Caster Semenya and Dutee Chand -- both of whom have intersex variations -will be eligible to compete in women's international sport reveals just how "elusive" this quest is. In the end, the International Olympic Committee stipulated categories of "sport sex" -- categories based on a combination of chromosomes and reproductive organs -relevant only to elite international sport, and arguably motivated more by racial prejudices than competitive relevance. ${ }^{64}$ All of that to say: Byrne's claim that a single, fixed category answers to "the" category adult human female is ignorant of the history and sociology of sex categorization.

\footnotetext{
${ }^{60}$ (Meyerowitz 2004), pp. 21-22. Emphasis added.

${ }^{61}$ (Meyerowitz 2004), p. 2.

${ }^{62}$ See, e.g., (K. A. Karkazis 2008).

${ }^{63}$ See, e.g., Richardson (in progress), which carefully demonstrates that, even just within biomedical research, definitions of sex widely vary.

${ }^{64}$ (K. Karkazis and Jordan-Young 2018)
} 
Second, for any one of the many possible binary categorizations of sex traits, there are none where these traits are shared universally among the group of people considered women (or men), even in dominant contexts. Medical anthropologist Katrina Karkazis points out that a century-long search for such traits has come up empty:

For a century, scientists studied an array of human characteristics that inform our ideas of what sex is, seeking to pin down a single, definitive biological indicator. Bodies troubled these schemes and led to socially untenable categorisations. If gonads were understood as the essence of sex, women who were phenotypically female but who had testes were men. This didn't make sense, so scientists proposed yet other traits. Even as they debated which biological trait signalled its essence, scientists understood sex as biological and involving multiple, if contested, factors. ${ }^{65}$

Despite this dead-end, commitment to binary sex classification still persists, leading to shoddy research and inconsistent definitions. For example, Sarah Richardson (2013) describes how attempts to justify binary classification using $X$ and $Y$ chromosomes led scientists to distort or gloss over evidence undermining this framework. ${ }^{66}$ And the U.S. government's attempt to define binary sex classifications resulted in inconsistent definitions -- one in terms of natal genitalia, and another in terms of "immutable biological traits". ${ }^{67}$ In short, as Kessler and McKenna observed in 1978, "There are [no features] that always and without exception are true of only one gender." 68 As we continue to learn more about the complexities of sex -- down to the fact that a single person can have different chromosomal sexes across cells ${ }^{69}$-- this forty-year-old observation becomes ever more well-founded.

Given this litany of failed attempts to locate a "single, definitive biological indicator" of binary sex classification, why do people continue to look for this indicator, or to insist that sex is universal and fixed? Moreover, what motivates the classifications of sex traits -- i.e., what explains why some traits but not others are understood as male or female traits?

In addressing these questions, we see the important sense in which biological sex categories also are social categories. Cultural beliefs about gender ${ }^{70}$, technology, and

65 (K. Karkazis 2019). See also (Fausto-Sterling 2012).

${ }^{66}$ (Richardson 2013) cf (K. Karkazis 2019)

${ }^{67}$ See discussion in (K. Karkazis 2019).

${ }^{68}$ (Kessler and McKenna 1978), p. 2.

${ }^{69}$ (Ainsworth 2015)

${ }^{70}$ In this, I include beliefs about persons who stand at intersections of gender with race, ethnicity, disability, age, and class -- see, e.g., (K. Karkazis and Jordan-Young 2018; Gill-Peterson 2018;

Snorton 2017). 
medical practices all are relevant to answering these questions. "Human sexual difference is seemingly obvious and certainly real on many levels," argues Anne Fausto-Sterling, "but in another sense it is a carefully crafted story about the social relations of a particular historical time and place, mapped onto available bodies. ${ }^{\prime 71}$ In saying this, Fausto-Sterling echoes what others also have observed: a social interest in maintaining binary gender categories women and men, basing those categories on physical features, and using those categories to restrict sexual and social behavior, motivates the imposition of binary classification onto features that are in fact varied and mosaic. It also motivates appeals to medicine and science to justify such imposition. ${ }^{72}$ As Karkazis writes, "What was thought to be the base or root of gender difference [i.e., sex] is actually an effect of gender."73 Along the same lines, linguist Lal Zimman points out that this effect is particularly visible once we observe the diversity across cultures concerning how sex features relate to social gender categories. ${ }^{74}$

I won't rehash the many detailed arguments for these claims here. A plethora of books and articles have been written on these issues. My point is simply this: Byrne's stipulated distinction between the "biological" and the "social" fails to show that they are exclusive, fails to undermine the traditional sex/gender distinction, and fails to show that sex categories are not, in the relevant and interesting sense, social categories. Moreover, the available evidence suggests that sex categories are ontologically multiple, not universal or directly mapping onto everyday gender categorization, and shaped by historical and cultural interests.

\section{Conclusion}

I've addressed Byrne's arguments largely on their own terms. I've shown that these arguments are uninformed and poorly constructed, and set aside their larger methodological and ethical problems. In closing, however, I want to pause to touch on these problems.

Byrne exhibits what Kessler and McKenna call the "natural attitude" concerning gender. In this natural attitude, we find a series of assumptions: there are two universal

\footnotetext{
${ }^{71}$ (Fausto-Sterling 1995), p. 21. cf (K. A. Karkazis 2008), p 6.

${ }^{72}$ See (K. A. Karkazis 2008), p. 12: "Our insistence on a so-called true sex is tied to a deep and abiding social interest that individuals engage in "correct" (I.e., socially sanctioned) forms of sexual behavior... The moral interest in limiting licentious behaviors...has driven the social interest in the medical determination of a single true sex."

${ }^{73}$ (K. A. Karkazis 2008), p. 13. "“'Dichotomous gender, far from being natural or innate, or based in our being, is accomplished, constructed, and reproduced in interactions and interpretive processes." See also (Kessler and McKinna 1978), p. 163: "Biological, psychological, and social differences do not lead to our seeing two genders. Our seeing two genders leads to the "discovery" of biological, psychological, and social differences." See also Butler 1990.

${ }^{74}$ (Zimman 2014)
} 
genders, every person immutably has one, and all this is vindicated by science. Other ways of seeing the world are, to someone with the natural attitude, 'ideological', 'primitive', or 'unscientific'. ${ }^{75}$

Finding this attitude at a family reunion or from certain riders on Byrne's "Clapham Omnibus" is not surprising. ${ }^{76}$ But finding this attitude unexamined and on display in a scholarly paper, where one is expected to be responsive to existing literature, empirical evidence, and relevant testimony, is quite another thing. In setting out with the question 'what is a woman?', philosophers must be aware that proposed answers bear real-world consequences for people -- including persons with intersex variations, women of color, and trans and gender nonconforming persons. Despite Byrne's misrepresentations, feminist metaphysicians do not take this awareness to mean that we should construct whatever definition would least offend, or would best cater to the wishes of these groups. Rather, we take this awareness to place a moral obligation on us to be particularly scrupulous, rigorous, and informed about our subject matter. Doing so requires demonstrating sensitivity to relevant existing literature, both inside and outside of analytic philosophy, as well as understanding this issue's stakes and complexity.

Byrne stipulates frameworks and assumptions that casually dismiss or ignore relevant existing literature. They cite the testimony of trans persons only for the purpose of undermining these persons' self-understanding, or for pitting them against other trans persons. ${ }^{77}$ Rather than take account of ways that definitions of sex categories impact persons with intersex conditions or from marginalized racial and ethnic groups, they sweepingly dismiss cultures with nonbinary gender systems in a footnote. ${ }^{78}$ They conjure a fictional intersex variation for the purpose of arguing that, no matter how much an intersex person looks, behaves, or claims to be a woman, they are not one. ${ }^{79}$ Byrne's paper fundamentally is an unscholarly attempt to vindicate a political slogan that is currently being used to undermine civic rights and respect for trans persons. And it is here that I return to Byrne's advice to question the motivations behind this debate. "If someone is personally heavily invested in the truth of p," Byrne writes, "it is prudent to treat [their] claim that $\mathrm{p}$ is true with some initial caution." ${ }^{180}$ I agree. So we may ask:

\footnotetext{
${ }^{75}$ (Kessler and McKenna 1978), pp. 4-5.

${ }^{76}$ Byrne, p. 1. ("Are women (simply) adult human females? It might surprise the woman on the Clapham Omnibus to learn that philosophers almost always answer no.")

${ }^{77}$ Byrne pp. 16-17.

${ }^{78}$ Byrne p. 10, fn 16.

${ }^{79}$ See Byrne p. 11. ("[Intersex] individuals behave and look just like (human) females. But behaving and looking like a female is not sufficient for being one. By any reasonable standard, CAS individuals are not female.")

${ }^{80}$ (Byrne 2020), p. 20.
} 
What are the motivations of someone who would so confidently insert themself into this high-stakes discourse while so ill-informed ${ }^{81} 82$

\section{Works Cited}

Ainsworth, C. 2015. "Sex Redefined." Nature 518 (7539).

Barnes, E. 2019. "Gender and Gender Terms." Nous. https://philpapers.org/rec/BARGAG-6.

Bettcher, T. 2009. "Trans Identities and First-Person Authority." In "You've Changed": Sex Reassignment and Personal Identity, edited by L. Shrage. Oxford: Oxford University Press. . 2013. "Trans Women and the Meaning of 'Woman.'" In Philosophy of Sex: Contemporary Readings, edited by A. Soble, N. Power, and R. Halwani, 6th ed., 233-50. Rowan \& Littlefield. https://philpapers.org/rec/BETQWA.

— 2018. "When Tables Speak: On the Existence of Trans Philosophy." Blog. Daily Nous (blog). May 30, 2018.

http:/ / dailynous.com/2018/05/30/tables-speak-existence-trans-philosophy-guest-taliamae-bettcher/.

Brison, S. 2019. "Can We End the Feminist 'Sex Wars' Now? Comments on Linda Martín Alcoff, Rape and Resistance: Understanding the Complexities of Sexual Violation." Philosophical Studies, $1-7$.

Burgess, A. and D. Plunkett. 2013. “Conceptual Ethics I." Philosophy Compass 8 (12): 1091-1101.

Butler, J. 1993. Bodies That Matter : On the Discursive Limits of "Sex." New York: Routledge.

Byrne, A. 2020. "Are Women Adult Human Females?" Philosophical Studies.

Corredor, E. 2019. “Unpacking 'Gender Ideology' and the Global Right's Antigender Countermovement." Signs: Journal of Women in Culture and Society 44 (3): 613-38. https://doi.org/10.1086/701171.

Crenshaw, K. 1989. “Demarginalizing the Intersection of Race and Sex: A Black Feminist Critique of Antidiscrimination Doctrine, Feminist Theory and Antiracist Politics." University of Chicago Legal Forum, no. 1: 139-67.

Dembroff, R. forthcoming. "Real Talk on the Metaphysics of Gender." Philosophical Topics.

Dembroff, R. and D. Wodak. 2018. "He/She/They/Ze." Ergo, an Open Access Journal of Philosophy 5. http://dx.doi.org/10.3998/ergo.12405314.0005.014.

Diaz-Leon, E. 2016. “Woman as a Politically Significant Term: A Solution to the Puzzle." Hypatia 31 (2): 245-258. https://doi.org/10.1111/hypa.12234.

Dotson, K. 2012. “How Is This Paper Philosophy?" Comparative Philosophy 3 (1): 03-29.

Ereshefsky, M. 1998. Species Pluralism and Anti-Realism. Philosophy of Science, 65(1), 103-120.

Fadulu, L. and A. Flanagan. 2019. “Trump's Rollback of Transgender Rights Extends Through Entire Government." The New York Times, December 6, 2019, sec. U.S. https://www.nytimes.com/2019/12/06/us/politics/trump-transgender-rights.html.

Fausto-Sterling, A. 2012. Sex/Gender: Biology in a Social World. The Routledge Series Integrating Science and Culture. New York: Routledge.

Fine, K. 1994. Essence and modality. Philosophical Perspectives, 8, 1-16.

Foucault, M. 1972. The Archaeology of Knowledge and the Discourse on Language. Translated by S. Smith. New York: Pantheon.

Gill-Peterson, J. 2018. Histories of the Transgender Child. Minneapolis : (Baltimore, Md: University

${ }^{81}$ See (Bettcher 2018) for further elaboration on this criticism.

${ }^{82}$ Many thanks to Lori Gruen, Katharine Jenkins, Karen Jones, Katrina Karkazis, Suzy Killmister, Hannah McCann, Naomi Scheman, and two anonymous referees at Philosophical Studies for helpful conversation and feedback during the development of this paper. 
of Minnesota Press, Project MUSE.

Haslanger, S. 2012. Resisting Reality : Social Construction and Social Critique. New York: Oxford University Press.

Hill Collins, P. 2000. Black Feminist Thought : Knowledge, Consciousness, and the Politics of Empowerment. New York: Routledge.

. 2016. Intersectionality. Malden, MA: Polity Press.

Jenkins, K. 2018. "Toward an Account of Gender Identity." Ergo: An Open Access Journal of Philosophy 5. http://dx.doi.org/10.3998/ergo.12405314.0005.027.

Karkazis, K. 2019. “The Misuses of 'Biological Sex.'” The Lancet 394 (November).

- 2008. Fixing Sex: Intersex, Medical Authority, and Lived Experience. Durham: Duke University Press.

Karkazis, K. and R. Jordan-Young. 2018. The Powers of Testosterone: Obscuring Race and Regional Bias in the Regulation of Women Athletes. https:/ / doi.org/10.13140/RG.2.2.19472.71681.

Kessler, S. and W. McKenna. 1978. Gender: An Ethnomethodological Approach. University of Chicago Press.

Kitcher, P. 1984. Species. Philosophy of Science, 51(2), 308-333.

Laclau, E. 2005. "Populism: What's in a Name?" In Populism and the Mirror of Democracy, edited by Francisco Panizza, 32-49. Verso.

Lakoff, R. 1973. “Language and Woman's Place." Language in Society 2 (1): 45-80.

Laskowski, N. G. 2020. Moral Constraints on Gender Concepts. Ethical Theory and Moral Practice, 23(1), 39-51.

Meyerowitz, J. 2004. How Sex Changed a History of Transsexuality in the United States. Cambridge, MA: Harvard University Press.

Mikkola, M. 2016. The Wrong of Injustice : Dehumanization and Its Role in Feminist Philosophy. New York, NY: Oxford University Press.

Nolan, D. 2014. Hyperintensional metaphysics. Philosophical Studies, 171(1), 149-160.

Richardson, S. (in progress) "Sex Contextualism"

- 2013. Sex Itself: The Search for Male and Female in the Human Genome. University of Chicago Press.

Saul, J. 2012. "Politically Significant Terms and Philosophy of Language." In Out from the Shadows: Analytical Feminist Contributions to Traditional Philosophy, edited by S.L. Crasnow and A.M. Superson. Oxford: Oxford University Press.

Schaffer, J. 2009. On what grounds what. In D. J. Chalmers, D. Manley, \& R. Wasserman (Eds.), Metametaphysics (pp. 347-383). New York: Oxford University Press.

Scheman, N. 1997. "Queering the Center by Centering the Queer: Reflections on Transsexuals and Secular Jews." In Feminists Rethink the Self, edited by Diana Meyers, 124-62. Westview Press.

Snorton, C. Riley. 2017. Black on Both Sides: A Racial History of Trans Identity. University of Minnesota Press.

Spelman, E. 1988. Inessential Woman : Problems of Exclusion in Feminist Thought. Boston: Beacon Press.

Thomas, D. 2019. “My Transgender Diary: 'My New Face Is Not yet a Pretty Sight.'” The Telegraph, December 12, 2019.

https:/ / www.telegraph.co.uk/health-fitness/body/transgender-diary-new-face-not-yetpretty-sight/.

Valentine, D. 2007. Imagining Transgender: An Ethnography of a Category. Duke University Press.

Wittig, M. 1985. "The Mark of Gender." Feminist Issues 5 (2): 3-12. https://doi.org/10.1007/BF02685575.

Zimman, L. 2014. The Discursive Construction of Sex: Remaking and Reclaiming the Gendered Body in Talk about Genitals among Trans Men. Oxford University Press. 
https:/ / www.oxfordscholarship.com/view /10.1093/acprof:oso/9780199937295.001.0001 /acprof-9780199937295-chapter-2. 